\title{
Örgütsel Belirsizliğin Örgütsel Bağlılık Üzerindeki Etkisinde Örgütsel Stresin Aracılık Rolü
}

DOI: $10.26466 /$ opus.748687

\author{
*

\begin{abstract}
A.Elif Yazgan* - Ebru Özer Topaloğlu **
* Dr.Öğr.Üyesi, Necmettin Erbakan Üniversitesi, Uygulamalı Bilimler Fakültesi, Konya/Türkiye E-Posta: aelifyazgan@gmail.com

ORCID: 0000-0002-3065-7930

** Öğr.Gör., Necmettin Erbakan Üniversitesi, Uygulamalı Bilimler Fakültesi, Konya/Türkiye E-Posta: ebruozerrr@gmail.com

ORCID: 0000-0002-7092-7624
\end{abstract}

Öz

Günümüzde işletmelerde ve teknolojide yaşanan hızlı değişimler sonucunda örgütlerdeki yöneticiler ve çalışanlar için belirsizlikler ortaya çıkmaktadır. İş hayatında yaşanan örgütsel bazdaki belirsizlikler de örgütsel strese neden olmaktadır. Örgütlerde yaşanan stres ise çalışanların örgütsel bağlllıkların etkilemektedir. Bu çalışmanın amacl, örgütsel belirsizliğin örgütsel bağlllık üzerindeki etkisinde örgütsel stresin aracılık rolünü belirlemektir. Araştırmanın örneklemi Konya İli merkez ilçelerde çalışan ve kolayda örnekleme yöntemiyle seçilen 212 banka çalışanıdır. Veri toplama aracı olarak kullanılan anket formunda örgütsel stres, örgütsel bağlllık ve örgütsel belirsizlik algısı ölçeklerinden yararlamılmıştır. SPSS paket programina veri girişi yapıldıktan sonra faktör analizinden, korelasyon analizinden ve değişkenler arasındaki yordayıcı ilişkilerin belirlenmesi maksadıyla geliştirilen modelin testinde yapısal eşittlik modellemesinden yararlanılmıştır. Araştırma sonucunda örgütsel belirsizliğin örgütsel bağhllı̆̆ negatif yönde yordadı̆̆ğ; örgütsel stres ile örgütsel örgütsel belirsizlik arasinda pozitif yönde; örgütsel belirsizlik ile örgütsel bağlılık arasında da negatif yönde bir ilişki olduğu; ayrıca örgütsel stresin örgütsel belirsizlik ve örgütsel bağhllık arasındaki ilişkide aracı etkiye sahip olduğu görülmüştür

Anahtar Kelimeler: Örgütsel belirsizlik, Örgütsel stres, Örgütsel bağhllık 


\title{
The Mediator Role of Organizational Stress on The Effect of Organizational Uncertainty on Organizational Commitment
}

\begin{abstract}
Today, as a result of rapid changes in businesses and technology, uncertainty emerges for managers and employees in organizations. Organizational uncertainties in business life also cause organizational stress. Stress experienced in organizations affects organizational commitment of employees. The aim of the research is assign the mediator role of organizational stress in the effect of organizational uncertainty on organizational commitment. The sample of this study is 212 bank employees working in central districts of Konya and selected by easy sampling method. Organizational stress, organizational commitment and organizational uncertainty perception scale were accessed in questionnaire form created to collect data. After entrying the data to SPSS package program, was used factor analysis, correlation analysis and structural equation modeling were accessed in test of the model created to assign the predictive relationships between the variables. Consequently, organizational uncertainty predicted organizational commitment negatively; positive direction between organizational stress and organizational organizational uncertainty; A negative relationship was set up between organizational uncertainty and organizational commitment. Also it is seen that organizational stress is a mediator effect in relationship among organizational uncertainty and organizational commitment.
\end{abstract}

Keywords: Organizational uncertainty, Organizational stress, Organizational commitment 


\section{Giriş}

İş hayatında zaman baskısının ve rekabetin arttığı, dünyada değişimin hızlandığı günümüzde belirsizlik ve buna bağlı olarak da streste artmaktadır. Stres, bireyin baskıya tepkisi olarak görülebilmektedir. İş hayatında ve ekonomide yaşanılan dalgalanmalar belirsizliğe ve dolayısıyla da örgütsel strese neden olmaktadır (Weinberg, vd., 2010). Örgütsel bağlılık bir çalışanın örgütün üyesi olarak kalma arzusu olarak açıklanmaktadır. Örgütsel bağlılık, bir çalışanın örgütün bir üyesi olarak kalmasını veya başka bir iş için mevcut işinden ayrılmasını etkilemektedir (Colquitt, vd., 2015).

Bu çalışmada zaman baskısının ve rekabetin çalışanlar tarafından fazlasıyla hissedildiği bankacllık sektöründe örgütsel belirsizliğin örgütsel bağlllık üzerindeki etkisinde örgütsel stresin aracı rolü belirlenmeye çalışılmıştır. Konya ili merkez ilçelerinde çalışan bankacılara uygulanan bu çalışmada bankacıların örgütsel belirsizlik, örgütsel bağlllık ve örgütsel strese ilişkin algılamaları ve ilişkileri ölçülmüş, örgütsel stresin aracılık rolü örgütsel belirsizliğin örgütsel bağlllı̆̆a etkisi üzerinden araştırılmıştır. Literatürde bu üç kavramın birlikte incelendiği başka bir çalışmaya rastlanmamıştır. Fakat literatür tarandığında bu üç kavramın ilişkili olabileceği tespit edilmiştir. O nedenle bu üç kavramın ilişkisi iç ve dış baskının ağır olduğu bankacılık sektöründe araştırılmıştır.

\section{Kavramsal Çerçeve}

\section{Örgütsel Stres}

Türk Dil Kurumu'nun ruhsal gerilim olarak tanımladığı stres genel itibariyle bireyleri etkileyen ve onların davranışların değiştirmelerine neden olan durum veya olayların ortaya çıkardığı gerilimdir (TDK, 2020a; Sökmen, 2010). Stres, birey tarafindan hem diş baskılara hem de bireyin kendinden kaynaklanan içsel baskılara karşı gösterdiği reaksiyon sonucunda fizyolojik, psikolojik ve davranışsal değişikliklere yol açan bir durumdur (Cranwell-Ward ve Abbey, 2005). Örgütlerde stres, çalışanın sağlı̆̆ ve refahının belirlenmesinde kritik bir faktördür ve aynı zamanda stresin örgütsel etkinliğin üzerinde önemli etkileri vardır (Ganster, vd., 1982). Örgütsel stres kişinin kendisi ne- 
deniyle, kişinin başkalarıyla olan ilişkileri sonucunda; kişinin işi ve işyerindeki ilişkileri ile ortaya çkabilmektedir (Cranwell-Ward ve Abbey, 2005). Çalışanlar, kendi plan ve programlarını istedikleri gibi hayata geçiremedikleri zaman ya da dışarıdan gelen baskıyla değiştirmeleri gerektiğinde stres yaşamaktadırlar (Sökmen, 2010).

Örgütsel strese sebep olan durumlar şöyledir (Zencirkıran ve Keser, 2018; Güney, 2007):

- Örgütün fiziksel çevre koşulları,

- İşin özellikleri,

- Rol çatışması / belirsizliği,

- Fazla /düşük iş yükü,

- Artan çalışma saatleri,

- İş güvenliğinin olmaması,

- Adaletsizlik,

- İşin monotonlaşması,

- Ücret yetersizliği,

- Terfi imkânlarının kısıtlı olması,

- Çalışma saatlerinin uzun olması,

- Zaman baskısı,

- Yetki eksikliği.

Çalıştığı örgütte stres altında olan bir çalışanda şu durumlar görülebilmektedir (Sutherland ve Cooper, 2000):

- İşe geç kalır veya işten erken ayrılabilir.

- İşe uzun aralar verebilir.

- Konsantrasyon düşüklüğü veya karar vermede zayıf kalması nedeniyle daha fazla hata yapabilir.

- Kalite denetimlerini reddedebilir.

- İşlerinin son teslim tarihini kaçırabilir.

- Stres altındaki çalışanlarda iş kazası daha çok görülebilir.

- İş arkadaşları ile çatışmalar yaşayabilir.

- Yenilikçilik ve yaratıcılık konusunda sıkıntı yaşayabilir. 


\section{Örgütsel Belirsizlik}

Belirsiz olma durumu olarak tanımlanan belirsizlik kavramı, örgütlerde örgütün yaşamsal varlı̆̆ını riske sokmaya kadar uzanan ciddi sonuçları doğurabilecek temel bir sorundur (Dinçman, 2016; TDK, 2020b). Belirsizlik çevrenin bir özelliği ya da psikolojik bir durum olarak tanımlanmaktadır (Bordia, vd., 2004). Belirsiz bir durum, yeterli ipucu olmaması nedeniyle birey tarafindan yeterince yapilandırılamayan veya kategorize edilemeyen bir durum olarak tanımlanabilir (Stanley Budner, 1962). Örgütler, belirsizliğin ana sebeplerinden olan yenilik, karmaşıklık ve çözülmezlik dolayısıyla; kaotik, karmaşık ve belirsiz ortamlar içerisinde hayatlarını sürdürmeye çalışmaktadır (Polat ve Arabac1, 2015). Örgütler, bu değişimlerden zarara uğramadan, kolay uyum sağlayacakları biçimde stratejiler geliştirmelidirler (Dinçman, 2016). Çalışanlar için belirsizliğe neden olan en önemli sebep örgütsel değişim ve iş güvencelerinin olmaması algıları ile ilgilidir (Hui ve Lee, 2000). Örgütlerde belirsizliğin arzu edilmemesinin nedeni verimlilik ve performansın önünde engel olabilmesinden kaynaklanmaktadır (Tinaztepe, 2010).

\section{Örgütsel Bağglllk}

Bireyin davranışı bağlılığının göstergesidir ve bu nedenle de bireyin ortaya koyduğu davranışlara göre bağlllığı anlaşılabilir (Salancik, 1977). Bir işletmeye bağl1lık üye temelli olacaktır çünkü üyenin bağl1lığıyla sonuçlanan olayların odağı kendi önceki davranışıdır (Angel ve Perry, 1983). Örgütsel bağlılık, çalışanın örgütünün hedefleri ile özdeşleştiği ve hedeflerini kolaylaştırmak için örgütünde çalışmayı sürdürmek istediği bir durum olarak tanımlanmaktadır (Blau ve Boal, 1987). Örgütün ve çalışanın amaçlarının gittikçe daha fazla bütünleştiği ya da uyumlu olmaya başladığı bir aşamadır (Hall, Schneider, ve Nygren, 1970). Örgütsel bağll1ık, çalışan ve onun çalıştığ örgütün arasındaki bağın kuvvetini gösteren bir tutumdur (Aycan, vd., 2014). Çalışanların kişisel özellikleri, değerleri, inançları, işten beklentileri, seçtikleri işin özellikleri gibi faktörler çalışanların örgütsel bağllık düzeylerini etkilemektedir (Mowday, vd., 1982).

1990 yılında Allen ve Meyer tarafından yapılan araştırmanın sonucuna göre örgütsel bağlılığı oluşturan öğeler duygusal bağlılık, devamlı bağlılık 
(devam etme isteği) ve normatif (zorunluluk) bağll1ık olarak üçe ayrılmaktadır. Duygusal bağlllıkta, kişisel faktörler, işle ilgili durumlar, işteki hayat ve yapısal faktörler olarak çeşitli sınıflandırmalar belirtmişlerdir. Duygusal bağlılığın yüksek olduğu çalışanlar, örgütün değerlerini güçlü bir şekilde benimserken örgütte hep yer almayı istemektedir (Çetin, 2004). Devam bağımlılığında ise çalışanlar mevcut işlerinden ayrılmak istediklerinde eğer alternatif bir iş yoksa bulundukları örgütte güçlü bir şekilde devamlılık bağımlılı̆̆ı hissedeceklerdir (Allen ve Meyer, 1990). Yaş, örgütte kaç yıldır çalıştıkları, terfi olanakları, örgütten ayrılma niyeti ve iş devri devam bağımlılı̆̆ ile ilişkilidir (Balay, 2000). Normatif bağımlılıkta ise örgüte sadakatle bağlanıp, örgütün görev, hedef ve icraatlarıyla uyum içerisindeki inanç ve normları kapsamaktadır (Allen ve Meyer, 1990). Örgütsel sosyalizasyon ve örgütün çalışanın eğitimi ve geleceği için yaptığı harcamalar normatif bağımlılığ lerdir (Özutku, 2008).

Örgütsel bağlllığı düşük düzeyde olan çalışanların yer almasının sonuçları şunlardır (Zencirkıran ve Keser, 2018):

- Düşük bağlılığa sahip çalışanlar olduğu zaman örgüt, çalışanından istediği performansı alamayacaktır.

- Çalışan, örgütüne bağlllığının düşük olduğu durumlarda çalışırken işi baştan savmak, iş yapıyormuş gibi bilinçli bir şekilde örgüte katkı sağlamayabilmektedir.

- Örgütüne bağlllığı düşük olan çalışan işyerinde daha az zaman geçirmek için işe geç gelebilir, işte erken çıkabilir ayrıca işe gitmemek için sağlık raporu alabilmektedir.

- Çalışan örgüte bağlılığı düşük olduğu zaman işten ayrılma yolunu da tercih edebilir.

\section{Literatür Taraması ve Araştırma Modeline İlişskin Hipotezler}

Araştırmanın konusunu oluşturan örgütsel belirsizlik, örgütsel stres ve örgütsel bağlllık konularıyla ilgili literatür taramasında ilk göze çarpan çalışma Duncan'ın (1972) algılanan belirsizlik üzerine yapmış olduğu çalışmadır. Ayrıca belirsizlik kavramını ve örgütsel belirsizliği kültürel bağlamda inceleyen (Faucheux, 1977; Hofstede 1980; Grote, 2007); örgütsel belirsizlik ve örgütsel strese örgütsel değişimin, örgütsel adaletin etkisinin araştırıldığı (Bordia, vd., 
2004; Rafferty ve Griffin, 2006); örgütsel stres ve örgütsel bağlllık ilişkisini inceleyen (Boshooff ve Mells, 1995; Ioannis ve Ioannis, 2002; Chen, vd., 2006; Lou,vd., 2007; Uzun ve Yiğit, 2011;) çalışmalar da mevcuttur. Literatüre bakıldığında örgütsel belirsizlik, örgütsel stres ve örgütsel bağlllık kavramlarının ilişkisi ayrı ayrı incelenmiştir. Bu çalışmada literatürde üzerine çalışılmamış olan örgütsel belirsizliğin örgütsel bağlllık üzerindeki etkisinde örgütsel stresin aracllık rolü araştıılarak literatüre katkı sağlamak amaçlanmıştır.

Araştırmayla ilgili literatür incelendikten sonra geliştirilen hipotezler aşağıdaki gibidir:

- H1: Örgütsel belirsizlik ile örgütsel bağl1lık arasında anlamlı ve negatif yönde bir ilişki vardır.

- $\mathrm{H}_{2}$ : Örgütsel belirsizlik örgütsel bağll1ı̆̆ı anlamlı ve negatif yönde etkilemektedir.

- $\quad \mathrm{H}_{3}$ : Örgütsel belirsizlik ile örgütsel stres arasında anlamlı ve pozitif yönde bir ilişki vardır.

- H4: Örgütsel stres ile örgütsel bağlllık arasında anlamlı ve negatif yönde bir ilişki vardır.

- $\mathrm{H}_{5}$ : Örgütsel belirsizliğin örgütsel bağlllı̆̆a etkisinde örgütsel stresin aracı rolü vardır.

Geliştirilen hipotezler kapsamında oluşturulan araştırma modeli ise aşağıdaki gibidir:

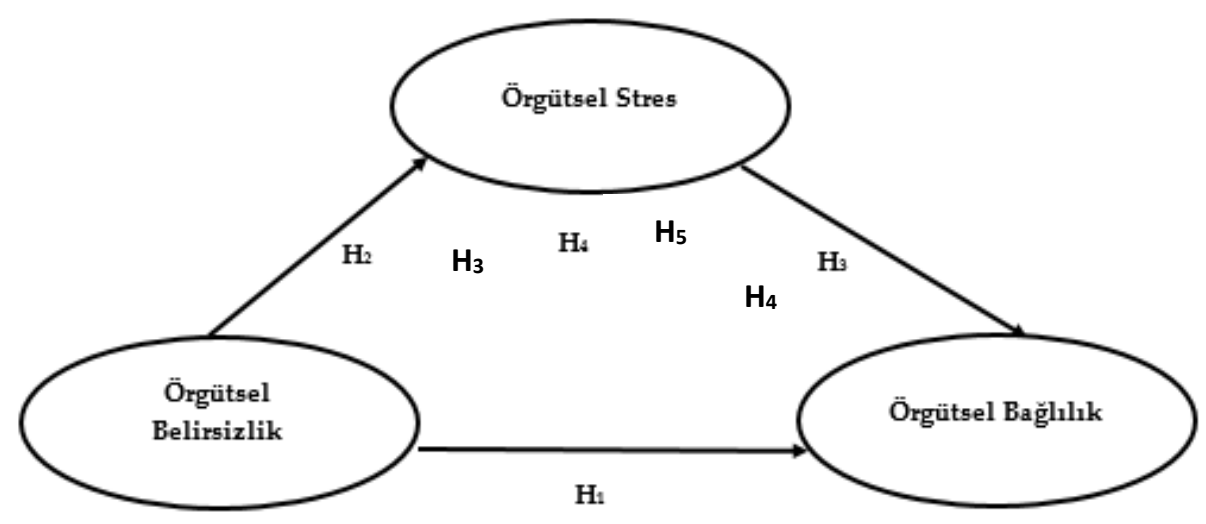

Şekil 1. Araştırmanın Kavramsal Modeli 


\section{Yöntem}

\section{Araştırmanın Örneklemi}

Araştırmanın evreni, Konya İli merkez ilçelerde çalışan bankacılardan oluşmaktadır. Örneklem ise ilgili merkez ilçelerde çalışan, kolayda örnekleme yöntemiyle seçilen ve Eylül- Aralık 2019 tarihleri arasında anket formları online olarak ulaştırılan 212 banka çalışanıdır. Araştırmaya katılan 212 banka çalışanının demografik sonuçlanı incelendiğinde; \% 44,3'ü kadınlardan, \% 72,6'sı lisans mezunu, \% 67'si özel banka çalışanından, \% 75'inin evlilerden oluştuğu ve ortalama yaşları 29,4 ve ortalama meslekte çalışma süreleri ise 10,48 yıl olarak ortaya çıkmıştır.

\section{Veri Toplama Araçları ve Geçerlilik Güvenirlik Analizleri}

Hipotezlerin testi için hazırlanan anket formunda dört bölüm bulunmaktadır. Birinci bölümde katılımcıların cinsiyet, yaş, eğitim durumu, konumu, çalışılan banka, aylık gelir gibi özelliklerini belirlemek amacıyla oluşturulan demografik sorular bulunmaktadır.

İkinci bölümde örgütsel stres düzeylerini ölçmede Theorelli ve arkadaşlarının (1988) geliştirdiği, Yıldırım ve arkadaşlarının (2011) Türkçe 'ye uyarlayıp geçerlilik ve güvenirliğini yaptığı 17 ifadeden oluşan ölçek kullanılmıştır. Ölçeğin bu araştırmadaki Cronbach Alpha değerinin 0,77 olduğu tespit edilmiştir.

Üçüncü bölümde örgütsel belirsizlik düzeylerini ölçmede Schweiger ve Denisi'nin (1991) geliştirdiği, Tinaztepe'nin (2010) Türkçe 'ye uyarlayıp geçerlilik ve güvenirliği yaptığı ölçek, Polat(2015)'tan alınarak kullanılmıştır. 21 ifadeden oluşan ölçeğin araştırmadaki Cronbach Alpha değerinin 0,859 olduğu tespit edilmiştir.

Dördüncü bölümde örgütsel bağlllık seviyelerini ölçmede Allen- Meyer'in (1990) geliştirdiği, Meyer ve arkadaşlarının (1993) revize ettiği ölçek Boylu ve arkadaşlarından (2007) alınarak kullanılmıştır. 17 ifadeden oluşan ölçeğin araştırmadaki Cronbach Alpha değerinin 0,888 olduğu tespit edilmiştir. 


\section{Verilerin Analizi}

Veri girişi IBM SPSS 25 paket programından yararlanılarak yapılmıştır. Veriler analiz edilirken değişkenlerle alakalı faktör analizi, değişkenler arasındaki ilişkilerin belirlenmesinde korelasyon analizi ve örgütsel belirsizliğin örgütsel stres ve örgütsel bağlılık ilişkisindeki aracı etkisinin incelenmesi amacıyla yapısal eşitlik modeli ile analizler yapılmıştır.

\section{Faktör Analizine İlişkin Bulgular}

Faktör analizine geçmeden önce araştırmada kullanılan ölçeklere (örgütsel stres, örgütsel belirsizlik ve örgütsel bağlllık) ait veri matrisinin korelasyonuna Kaiser-Meyer-Olkin (KMO) testiyle bakılmıştır. Araştırmada kullanılan örgütsel stres, örgütsel belirsizlik ve örgütsel bağlllık ölçeklerinin KMO örneklem yeterliliği değerleri sırasıyla 0,$788 ; 0,837$ ve 0,887 olarak tespit edilmiştir. Bulunan bu değerler örneklemin faktör analizine uygun olduğunu göstermektedir. (Büyüköztürk, 2007; Kline, 1994).Ayrıca, araştırmada kullanılan değişkenler arasındaki ilişki düzeyini gösteren Barlett Küresellik Testinin anlamlılık değerinin de 0,05'den küçük olması gerekmektedir. İlgili ölçeklere ilişkin Barlett Küresellik Testi sonuçlarına bakıldığında da bu ölçeklerin tamamında p değerinin 0,05'den küçük olduğu görülmüştür. Bu bulgular ışığında faktör analizlerine geçilmiş ve sonuçlar aşağıdaki tablolarda özetlenmiştir.

Tablo 1. Örgütsel stres ölçeğiyle ilgili faktör analizi bulgularn

\begin{tabular}{|c|c|c|c|c|}
\hline Boyutlar & Maddeler & Faktör Yükleri & Cronbach's Alpha & Toplam Varyans \\
\hline \multirow{5}{*}{ Sosyal Destek } & S13 & 0,777 & \multirow{5}{*}{0,820} & \multirow{14}{*}{66,816} \\
\hline & S14 & 0,767 & & \\
\hline & S15 & 0,704 & & \\
\hline & S16 & 0,582 & & \\
\hline & S17 & 0,784 & & \\
\hline \multirow{3}{*}{ Karar Verme } & S10 & 0,853 & \multirow{3}{*}{0,766} & \\
\hline & S11 & 0,814 & & \\
\hline & $\mathrm{S} 12$ & 0,637 & & \\
\hline \multirow{3}{*}{ İş Yükü } & S1 & 0,872 & \multirow{3}{*}{0,821} & \\
\hline & S2 & 0,878 & & \\
\hline & S3 & 0,776 & & \\
\hline \multirow[t]{3}{*}{ Beceri Kullanımı } & S6 & 0,677 & \multirow{3}{*}{0,702} & \\
\hline & S7 & 0,688 & & \\
\hline & S8 & 0,707 & & \\
\hline
\end{tabular}


Örgütsel stres ölçeğine yönelik yapılan faktör analizi sonucunda 4, 5 ve 9 . maddeler düşük faktör yükleri göstermeleri nedeniyle ölçekten çıkarılmış, geriye kalan 14 maddenin faktör analizi sonuçları tabloda özetlenmiştir. Toplam varyansın \%66,8'ini açıklayan ölçek literatürle uyumlu olarak dört alt boyutta toplanmıştır. Bu boyutlar sosyal destek, karar verme, iş yükü ve beceri kullanımı olarak ifade edilmektedir. Ölçeğin iç tutarlılık katsayısı sosyal destek boyutunda 0,820; karar verme boyutunda 0,766 ; iş yükü boyutunda 0,821 ve beceri kullanımı boyutunda 0,702 olarak tespit edilmiştir. Ölçeğin tamamına ilişkin iç tutarlılık katsayısının (3 madde çıkarıldıktan sonra) ise 0,78 olduğu görülmüştür. Bu sonuçlar ölçeğin ve alt boyutlarının güvenilirliğinin yüksek olduğunu göstermektedir.

Örgütsel belirsizlik ölçeğiyle ilgili faktör analizi bulguları aşağıdaki gibidir:

Tablo 2. Örgütsel belirsizlik ölçeğiyle ilgili faktör analizi bulgulan

\begin{tabular}{|c|c|c|c|c|}
\hline Boyutlar & Maddeler & Faktör Yükleri & Cronbach's Alpha & Toplam Varyans \\
\hline & B1 & 0,582 & & \multirow{17}{*}{60,732} \\
\hline Nedensel İlişkilerin & B10 & 0,627 & & \\
\hline \multirow[t]{7}{*}{ Genel Belirsizliği } & B14 & 0,766 & & \\
\hline & B15 & 0,785 & 0,850 & \\
\hline & B17 & 0,646 & & \\
\hline & B18 & 0,423 & & \\
\hline & B19 & 0,530 & & \\
\hline & $\mathrm{B} 20$ & 0,462 & & \\
\hline & B6 & 0,679 & \multirow{6}{*}{0,811} & \\
\hline \multirow[t]{6}{*}{ Bilginin Açık Olmaması } & B8 & 0,598 & & \\
\hline & B9 & 0,685 & & \\
\hline & B11 & 0,580 & & \\
\hline & B12 & 0,639 & & \\
\hline & B13 & 0,631 & & \\
\hline & B2 & 0,624 & \multirow{3}{*}{0,705} & \\
\hline Geri Bildirimin Uzun & B4 & 0,710 & & \\
\hline Zaman Alması & B21 & 0,604 & & \\
\hline
\end{tabular}

Örgütsel belirsizlik ölçeğine yönelik yapılan faktör analizi sonucunda 3, 5, 7 ve 16. maddeler düşük faktör yükleri göstermeleri nedeniyle ölçekten çıkarılmış, geriye kalan 17 maddenin faktör analizi sonuçları tabloda özetlenmiştir. Toplam varyansın \%60,7'sini açıklayan ölçek literatürle uyumlu olarak üç alt boyutta toplanmıştır. Bu boyutlar nedensel ilişkilerin genel belirsizliği, bil- 
ginin açık olmaması ve geri bildirimin uzun zaman alması olarak belirlenmiştir. Ölçeğin iç tutarlılık katsayısı nedensel ilişkilerin genel belirsizliği boyutu için 0,850; bilginin açık olmaması boyutu için 0,811 ve geri bildirimin uzun zaman alması boyutu için 0,705 olduğu bulunmuştur. Ölçeğin tamamına ilişkin iç tutarlılık katsayısının (4 madde çıkarıldıktan sonra) ise 0,87 olduğu görülmüştür.

Örgütsel bağlılık ölçeğiyle ilgili faktör analizi bulguları aşağıdaki gibidir:

Tablo 3. Örgütsel bağlılık ölçeğiyle ilgili faktör analizi bulgularn

\begin{tabular}{llllc}
\hline Boyutlar & Maddeler & Faktör Yükleri & Cronbach's Alpha & Toplam Varyans \\
\hline & B.1 & 0,707 & & \\
Duygusal Bağlllık & B. & 0,781 & & \\
& B.3 & 0,872 & 0,934 & \\
& B.4 & 0,883 & & \\
& B.5 & 0,892 & & \\
& B. & 0,723 & & \\
& B.8 & 0,534 & & \\
Devam Bağlllığ1 & B. & 0,851 & & \\
& B.10 & 0,523 & 0,756 & \\
& B.11 & 0,812 & & \\
& B.12 & 0,748 & & \\
Normatif Bağlllık & B.7 & 0,578 & & \\
& B.13 & 0,538 & & \\
& B.14 & 0,659 & 0,838 & \\
& B.15 & 0,744 & & \\
& B.16 & 0,724 & & \\
& B.17 & 0,774 & & \\
\hline
\end{tabular}

Tablo 3'e göre toplam varyansın \%67,5'ini açılayan ölçek litetatürle uyumlu olarak 3 alt boyutta toplanmıştır. Bu boyutlar duygusal bağlılık, devam bağlllığı ve normatif bağlllık olarak belirlenmiştir. Ölçeğin iç tutarlılık katsayısı duygusal bağlılıkta 0,934; devam bağllı̆̆ında 0,756 ve normatif bağlılıkta 0,838 olduğu bulunmuştur. Ölçeğin tamamına ilişkin iç tutarlılık katsayısının ise 0,888 olduğu görülmüştür.

\section{Tanimlayıcı Ístatistikler}

Çalışmada kullanılan ölçeklerin tanımlayıc istatistikleri ve normallik dağıllmına ilişkin bulgular tablosu Tablo 4 'te özetlenmektedir. 
Tablo 4. Çalışmadaki ölçeklerin tanımlayıcı istatistiklerine ilişkin bulgular

\begin{tabular}{lllll}
\hline Değişkenler & Ort. & S.S. & Çarpiklık & Basıklık \\
\hline Sosyal Destek & 20,36 & 3,530 & $-0,781$ & 0,435 \\
\hline Karar Verme & 10,01 & 2,796 & $-0,362$ & $-0,423$ \\
\hline İş Yükü & 12,95 & 1,920 & $-0,720$ & $-0,349$ \\
\hline Beceri Kul. & 11,92 & 2,136 & $-0,561$ & $-0,051$ \\
\hline Ned.İliş.Gen.Bel. & 30,26 & 7,621 & $-0,176$ & $-0,070$ \\
\hline Bil.Aç.Olm. & 25,41 & 5,445 & $-0,282$ & 0,502 \\
\hline Geri Bil.Uz.Zam.Alm. & 11,59 & 4,560 & $-0,189$ & 0,578 \\
\hline Duy.Bağ. & 22,27 & 6,143 & $-0,860$ & 0,253 \\
\hline Dev.Bağ. & 18,62 & 3,861 & $-0,662$ & 0,231 \\
\hline Norm.Bağ. & 21,08 & 5,420 & $-0,132$ & $-0,647$ \\
\hline
\end{tabular}

Özellikle sosyal bilimlerde normallik varsayımı, çarpıklık ve basıklık katsayılarına bakılarak incelenebilir. Tabachnick ve Fidell (2012), çarpıklık ve basıklık değerlerinin $-1,5$ ile $+1,5$ aralığında olduğunda veri setinin normal dağıldığını belirtmektedirler. Araştırmada ele alınan değişkenlerin bu varsayımları sağladığı görüldüğünden verilerin normal dağılıma uygun olduğu söylemek mümkündür.

\section{Korelasyon Analizi}

Değişkenler arasında ilişkinin tespitinde yapılan korelasyon analizi bulguları aşağıdaki tabloda özetlenmiştir.

Tablo 5. Korelasyon analizi sonuçlar

\begin{tabular}{|c|c|c|c|c|c|c|c|c|c|}
\hline & 1 & 2 & 3 & 4 & 5 & 6 & 7 & 8 & 9 \\
\hline 1 & - & & & & & & & & \\
\hline 2 & $503^{* *}$ & - & & & & & & & \\
\hline 3 & $316^{*}$ &,- 041 & - & & & & & & \\
\hline 4 &, $302^{* *+}$ & $405^{* *}$ & $279^{* *}$ & - & & & & & \\
\hline 5 & $280^{* *+}$ & $473^{* *}$ & ,015 & $284^{* *}$ & - & & & & \\
\hline 6 & $292^{* *}$ & $391^{* *}$ & , 130 & $273^{* *}$ & $661^{* *}$ & - & & & \\
\hline 7 & $154^{*}$ & 034 & $179^{* *}$ & 135 & $393^{* *}$ & $275^{* *}$ & - & & \\
\hline 8 &,$- 461^{* *}$ &,$- 424^{* *}$ &,- 062 &,$- 364^{* *}$ &,$- 462^{* *}$ &,$- 472^{* *}$ & 012 & - & \\
\hline 9 &,- 099 &,- 012 &,$- 348^{* *}$ &,$- 165^{*}$ & ,117 &,- 005 &,$- 130^{*}$ &, 063 & - \\
\hline 10 &,$- 335^{* *}$ &,$- 469^{* *}$ & , 070 &,$- 397^{* *}$ &,$- 496^{* *}$ &,$- 417^{* *}$ & $-128^{*}$ & $658^{* *}$ & $278^{* *}$ \\
\hline \multicolumn{10}{|c|}{${ }^{*} \mathrm{p}<, 05,{ }^{* *} \mathrm{p}<, 01$} \\
\hline \multicolumn{3}{|c|}{ 1. Sosyal Destek } & \multicolumn{2}{|c|}{ 2. Karar Verme } & 3. İş Yükü & \multicolumn{3}{|c|}{ 4. Beceri Kullanımı } & \\
\hline \multicolumn{5}{|c|}{ 5. Nedensel İlişkilerin Genel Belirsizliği } & \multicolumn{4}{|c|}{ 6. Bilginin Açık Olmaması } & \\
\hline \multicolumn{5}{|c|}{ 7. Geri Bildirimin Uzun Zaman Alması } & \multicolumn{4}{|c|}{ 8. Duygusal Bağlılık } & \\
\hline \multicolumn{5}{|c|}{ 9. Devam Bağlılığı } & \multicolumn{4}{|c|}{ 10. Normatif Bağlılık } & \\
\hline
\end{tabular}


Tablo 5'ten de görülebileceği örgütsel stresin alt boyutlarından sosyal destek, örgütsel belirsizliğin alt boyutlarından nedensel ilişkilerin genel belirsizliği $(\mathrm{r}=, 280, \mathrm{p}<.01)$, bilginin açık olmaması $(\mathrm{r}=, 292, \mathrm{p}<.01)$, geri bildirimin uzun zaman alması $(\mathrm{r}=, 154, \mathrm{p}<.05)$ boyutları ile pozitif yönde düşük düzeyde ilişkili bulunmuştur. Sosyal destek, örgütsel bağlllığın alt boyutlarından duygusal bağll1ık $(\mathrm{r}=-, 461, \mathrm{p}<.01)$, normatif bağllık $(\mathrm{r}=-, 335, \mathrm{p}<.01)$ boyutları ile negatif yönde orta düzeyde ilişkili bulunmuştur. Örgütsel stresin alt boyutlarından karar verme, örgütsel belirsizliğin alt boyutlarından nedensel ilişkilerin genel belirsizliği $(r=, 473, p<.01)$, bilginin açı olmaması $(r=, 391, p<.01)$ boyutları ile pozitif yönde orta düzeyde ilişkili bulunmuştur. Karar verme, örgütsel bağlllı̆̆ın alt boyutlarından duygusal bağlllık $(\mathrm{r}=-, 424, \mathrm{p}<.01)$, normatif bağlılık $(\mathrm{r}=-, 469, \mathrm{p}<.01)$ boyutları ile negatif yönde orta düzeyde ilişkili bulunmuştur. Örgütsel stresin alt boyutlarından iş yükü, örgütsel belirsizliğin alt boyutlarından geri bildirimin uzun zaman almasi $(\mathrm{r}=, 179, \mathrm{p}<.01)$ boyutu ile pozitif yönde zayıf düzeyde ilişkili bulunmuştur. İş yükü, örgütsel bağlllığın alt boyutlarından devam bağlılığı $(r=-, 348, p<.01)$ boyutu ile negatif yönde orta düzeyde ilişkili olduğu görülmüştür.

Örgütsel stresin alt boyutlarından beceri kullanımı, örgütsel belirsizliğin alt boyutlarından nedensel ilişkilerin genel belirsizliği $(\mathrm{r}=$,284, $\mathrm{p}<.01)$, bilginin açık olmaması $(\mathrm{r}=, 273, \mathrm{p}<.01)$ boyutları ile pozitif yönde zayıf düzeyde ilişkili bulunmuştur. Beceri kullanımı, örgütsel bağl1lı̆ın alt boyutlarından duygusal bağllı lı $(\mathrm{r}=-, 364, \mathrm{p}<.01)$, normatif bağlllık $(\mathrm{r}=-, 397, \mathrm{p}<.01)$ boyutları ile negatif yönde orta düzeyde; devam bağlllık $(r=-, 165, p<.05)$ boyutu ile de negatif yönde zayıf düzeyde ilişkili bulunmuştur.

Örgütsel belirsizliğin alt boyutlarından nedensel ilişkilerin genel belirsizliği, örgütsel bağlılığın alt boyutlarından duygusal bağlılık $(\mathrm{r}=-, 462, \mathrm{p}<.01)$, normatif bağll1lk ( $\mathrm{r}=-, 496, \mathrm{p}<.01)$ boyutları ile negatif yönde orta düzeyde ilişkili bulunmuştur. Örgütsel belirsizliğin alt boyutlarından bilginin açık olmaması, örgütsel bağlılığın alt boyutlarından duygusal bağlılık $(\mathrm{r}=-, 472, \mathrm{p}<.01)$, normatif bağl1lık $(\mathrm{r}=-, 417, \mathrm{p}<.01)$ boyutları ile negatif yönde orta düzeyde ilişkili bulunmuştur. Örgütsel belirsizliğin alt boyutlarından geri bildirimin uzun zaman alması, örgütsel bağlılı̆̆ın alt boyutlarından devam bağlılığı $(\mathrm{r}=$ $-, 130, \mathrm{p}<.05)$, normatif bağlılık $(\mathrm{r}=-, 128, \mathrm{p}<.05)$ boyutları ile negatif yönde zayıf düzeyde ilişkili bulunmuştur.

Çalışmaya konu olan aracılık etkisinden söz edebilmek için bağımsız değişkenin bağımlı ve aracı değişken ile ilişkili olması gerektiğine dair (Baron 
ve Kenny, 1986; Zengin, 2019: 1343) koşulun sağlanıp sağlanamadığına ilişkin analiz aşağıdaki tabloda özetlenmiştir.

Tablo 6. Ana değişkenlere ilişkin korelasyon analizi sonuçlan

\begin{tabular}{lllll}
\hline & Örgütsel Stres & Örgütsel Belirsizlik & Örgütsel Bağlllı \\
\hline Örgütsel Stres & - & & \\
\hline Örgütsel Belirsizlik &, $497^{* *}$ & - & \\
\hline Örgütsel Bağllılk &,$- 309^{* *}$ &,$- 401^{* *}$ & - \\
\hline
\end{tabular}

Tablodan görüldüğ̈̈ üzere, örgütsel belirsizlik ile örgütsel bağlllık ( $r$ = ,401, $\mathrm{p}<.01$ ) arasında negatif yönde orta düzeyde bir ilişki bulunmuş ve $\mathrm{H}_{1}$ hipotezi kabul edilmiştir. Örgütsel belirsizlik ile örgütsel stres $(r=, 497, p<.01)$ arasında pozitif yönde orta düzeyde bir ilişki bulunmuş ve $\mathrm{H}_{3}$ hipotezi kabul edilmiştir. Örgütsel stres ile örgütsel bağlılık $(r=-, 309, p<.01)$ arasında negatif yönde orta düzeyde bir ilişki bulunmuş ve $\mathrm{H}_{4}$ hipotezi kabul edilmiştir. $\mathrm{Bu}$ sonuçlar ışığında aracılık etkisine bakabilmek için gerekli olan koşulların sağlandığı görülmüştür.

\section{Doğrulayıcı Faktör Analizi(DFA)}

Ölçeğin yapı geçerliliğinin testinde Doğrulayıc Faktör Analizinden yararlanılmış ve DFA'ya ait uyum iyiliği değerleri aşağıdaki tabloda sunulmuştur.

Tablo 7. Yaptsal modelin uyum indeksleri

\begin{tabular}{llll}
\hline Model Uyum İndeksleri & Modelin Uyum Değerleri & \multicolumn{2}{c}{ Uyum Değerleri } \\
\cline { 3 - 4 } & & İyi & Kabul Edilebilir \\
\hline $\boldsymbol{2}$ /sd & 2,87 & $0 \leq \chi 2 / \mathrm{sd} \leq 3$ & $3 \leq \chi 2 / \mathrm{sd} \leq 5$ \\
\hline RMSEA & 0,08 & $0 \leq \mathrm{RMSEA} \leq 0,05$ & $0,05 \leq \mathrm{RMSEA} \leq 0,10$ \\
\hline AGFI & 0,94 & $0,90 \leq \mathrm{AGFI} \leq 1,00$ & $0,85 \leq \mathrm{AGFI} \leq 0,90$ \\
\hline GFI & 0,95 & $0,95 \leq \mathrm{GFI} \leq 1,00$ & $0,90 \leq \mathrm{GFI} \leq 0,95$ \\
\hline NFI & 0,92 & $0,95 \leq \mathrm{NFI} \leq 1,00$ & $0,90 \leq \mathrm{NFI} \leq 0,95$ \\
\hline TLI & 0,93 & $0,95 \leq \mathrm{TLI} \leq 1,00$ & $0,90 \leq \mathrm{TLI} \leq 0,95$ \\
\hline CFI & 0,95 & $0,95 \leq \mathrm{CFI} \leq 1,00$ & $0,90 \leq \mathrm{CFI} \leq 0,95$ \\
\hline SRMR & 0,06 & $0 \leq \mathrm{SRMR} \leq 0,05$ & $0,05 \leq \mathrm{SRMR} \leq 0,10$ \\
\hline Kaynak: & & &
\end{tabular}

Kaynak: Schermelleh-Engel ve diğ. ( 2003)

Araştırma modelinde $\chi 2 / s d$, AGFI, GFI, CFI değerleri iyi uyum sınırları içerisinde; RMSEA, NFI, TLI ve SRMR değerleri de kabul edilebilir uyum s1nırları içerisinde olduğundan modelin veri ile uyumlu olduğunu söylemek mümkündür. 
Araştırmanın amacı doğrultusunda geliştirilen yapısal eşitlik modeli aşağıdaki şekilde ve bu modele ilişkin regresyon ağırlıkları ise Tablo 7'de özetlenmiştir.

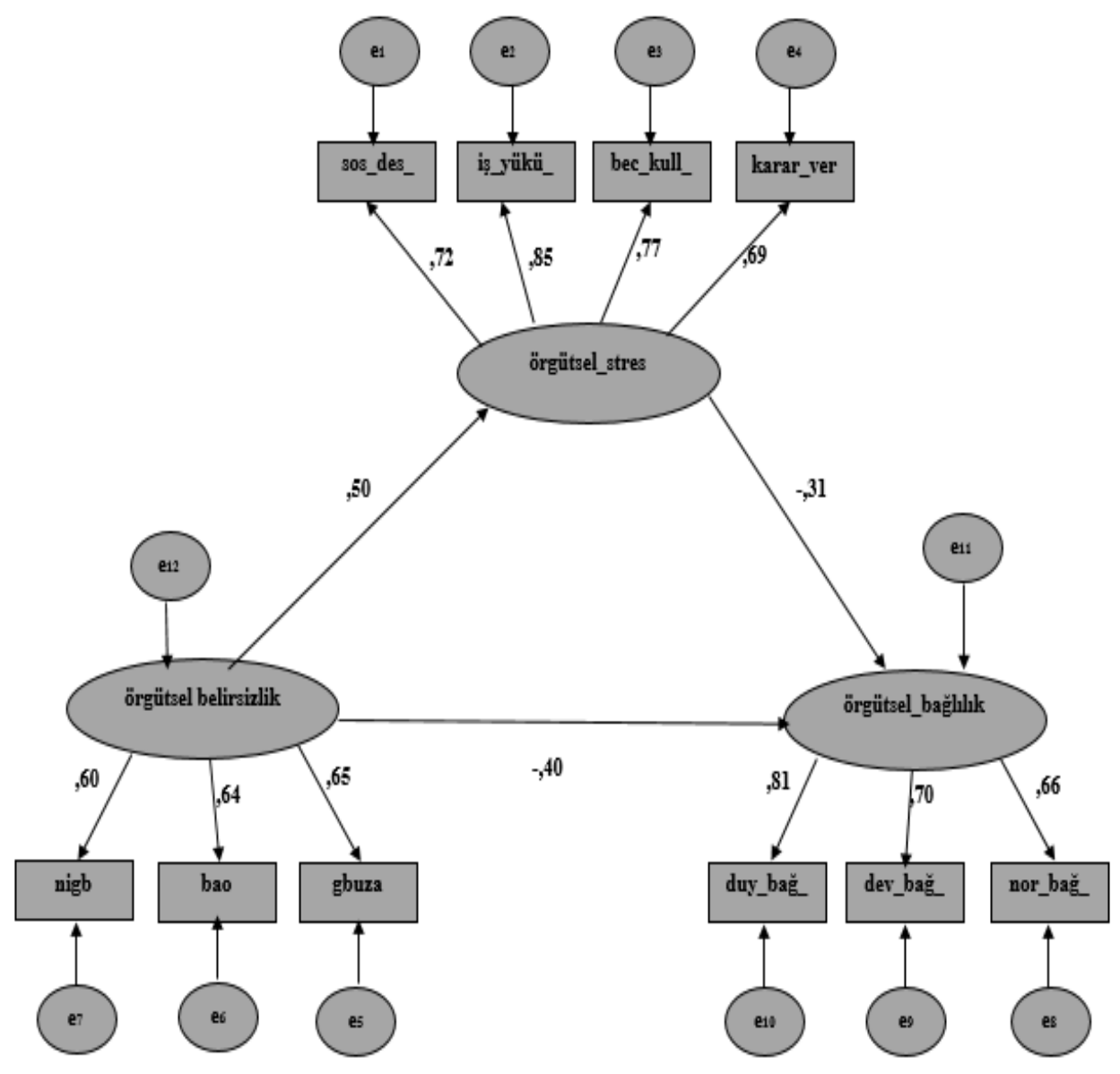

Şekil 2. Araştırmada Kullanılan Değişkenlere İlişkin Yapısal Eşitlik Modellemesi

Tablo 8. Yapısal eşitlik modeli regresyon ağırlıkları

\begin{tabular}{lllllll}
$\begin{array}{l}\text { Bağımlı Değiş- } \\
\text { ken }\end{array}$ & $\begin{array}{l}\text { Yordayıcr } \\
\text { Değisken }\end{array}$ & $\begin{array}{l}\text { Toplam } \\
\text { Etki }\end{array}$ & $\begin{array}{l}\text { Doğrudan } \\
\text { Etki }\end{array}$ & $\begin{array}{l}\text { Dolayli } \\
\text { Etki }\end{array}$ & S.H. & t \\
\hline Örgütsel Bağlllkk & Örgütsel Belirsizlik & $-0,42$ & $-0,23$ & $-0,19$ & 0,06 & $-5,37^{*}$ \\
\hline Örgütsel Stres & Örgütsel Belirsizlik & 0,29 & 0,29 & .0 & 0,07 & $3,21^{*}$ \\
\hline Örgütsel Bağılllk & Örgütsel Stres & $-0,44$ & $-0,44$ & .0 & 0,06 & $-4,97^{*}$ \\
\hline${ }^{*} \mathrm{p}<, 05,{ }^{*} p<<, 01$ & & & & & & \\
\hline
\end{tabular}


Oluşturulan yapısal eşitlik modelinden elde edilen sonuçlar örgütsel belirsizliğin örgütsel bağlılığı yordadığını göstermiştir $(\beta=-, 23, t=-5,37 p<.05)$. Aynı zamanda örgütsel belirsizlik örgütsel stresi de yordamaktadır $(\beta=, 29, \mathrm{t}$ $=3,21 \mathrm{p}<.05)$. Örgütsel stres de örgütsel bağlllı̆̆ negatif yönde yordamakta$\operatorname{dır}(\beta=-0,44, t=-4,97 p<.05)$. Örgütsel belirsizliğin örgütsel bağlllık üzerindeki etkisinde örgütsel stresin dolaylı etkisinin $\beta=-, 19(p<.05)$ olduğu tespit edilmiştir. Ayrıca bootstrapp analizi sonuçlarına bakıldığında da örgütsel belirsizlik ile örgütsel bağllılı arasındaki ilişkide örgütsel stresin kısmi aracı rolü olduğu görülmektedir(\%95 GA $[.07, .31])$. Bu bilgiler doğrultusunda $\mathrm{H}_{2}$ ve $\mathrm{H}_{5}$ hipotezleri de kabul edilmiştir.

\section{Sonuç ve Tartışma}

Çalışanların yaşadığı örgütsel belirsizlik, örgütsel bağlılık ve örgütsel stres arasındaki ilişkilerin incelendiği bu araştırmada; örgütsel stresin örgütsel belirsizlik ve örgütsel bağlllık arasındaki ilişkide aracı etkiye sahip olduğu görülmüştür.

Araştırma kapsamında yapılan korelasyon analizlerine göre örgütsel stresin alt boyutlarından sosyal destek, örgütsel desteğin alt boyutlarından nedensel ilişkilerin genel belirsizliği, bilginin açı olmaması, geri bildirimin uzun zaman alması boyutları ile pozitif yönde düşük düzeyde; örgütsel bağlılığın alt boyutlarından duygusal bağlılık, normatif bağlılık boyutları ile negatif yönde orta düzeyde ilişkili bulunmuştur. Örgütsel stresin alt boyutlarından karar verme, örgütsel belirsizliğin alt boyutlarından nedensel ilişkilerin genel belirsizliği, bilginin açı olmaması boyutları ile pozitif yönde orta düzeyde; örgütsel bağlllı̆̆ın alt boyutlarından duygusal bağlılık, normatif bağlılık boyutları ile negatif yönde orta düzeyde ilişkili bulunmuştur. Örgütsel stresin alt boyutlarından iş yükü, örgütsel belirsizliğin alt boyutlarından geri bildirimin uzun zaman alması boyutu ile pozitif yönde zayıf düzeyde; örgütsel bağlılığın alt boyutlarından devam bağlılığı boyutu ile negatif yönde orta düzeyde ilişkili olduğu görülmüştür. Örgütsel stresin alt boyutlarından beceri kullanımı, örgütsel belirsizliğin alt boyutlarından nedensel ilişkilerin genel belirsizliği, bilginin açık olmaması boyutları ile pozitif yönde zayıf düzeyde; örgütsel bağlllığın alt boyutlarından duygusal bağlllık, normatif bağlılık boyutları ile negatif yönde orta düzeyde; devam bağl1lık boyutu ile de negatif yönde zayıf düzeyde ilişkili bulunmuştur. 
Örgütsel belirsizliğin alt boyutlarından nedensel ilişkilerin genel belirsizliği, örgütsel bağlılığın alt boyutlarından duygusal bağlılık, normatif bağlllık boyutları ile negatif yönde orta düzeyde ilişkili bulunmuştur. Örgütsel belirsizliğin alt boyutlarından bilginin açı olmaması, örgütsel bağlllı̆ı̆ alt boyutlarından duygusal bağlılık, normatif bağlılık boyutları ile negatif yönde orta düzeyde ilişkili bulunmuştur. Örgütsel belirsizliğin alt boyutlarından geri bildirimin uzun zaman alması, örgütsel bağlılığın alt boyutlarından devam bağlılığı, normatif bağlılık boyutları ile negatif yönde zayıf düzeyde ilişkili bulunmuştur.

Araştırmanın ana değişkenleriyle ilgili korelasyon analizi sonuçlarına göre örgütsel belirsizlik ile örgütsel bağlllık arasında negatif yönde orta düzeyde; örgütsel belirsizlik ile örgütsel stres arasında pozitif yönde orta düzeyde; örgütsel stres ile örgütsel bağlllık arasında negatif yönde orta düzeyde bir ilişki bulunmuştur. Bu doğrultuda $\mathrm{H}_{1}, \mathrm{H}_{3}$ ve $\mathrm{H}_{4}$ hipotezleri kabul edilmiştir. Elde edilen sonuçlar literatürdeki diğer araştırmalarla uyum göstermektedir (Uzun ve Yiğit, 2011; Düzgün, 2004; Bilgili ve Tekin, 2019). Örgütsel belirsizlik azaldıkça çalışanların örgütlerine bağlılığı artmakta; örgütsel stres azaldıkça çalışanların örgütlerine bağlılıkları artmaktadır. Sonuç itibariyle çalışanlar belirsizlikten uzak stres altında olmadıkları müddetçe örgütlerine bağlılıklarını artacağını söyleyebiliriz.

Ayrıca yapısal eşitlik modelinden elde edilen sonuçlara göre örgütsel belirsizliğin örgütsel bağlllığı yordadığı; bootstrapp analizi sonuçlarına bakıld1ğında da örgütsel belirsizlik ile örgütsel bağlllık arasındaki ilişkide örgütsel stresin kısmi aracı rolü olduğu görülmektedir. $\mathrm{Bu}$ doğrultuda $\mathrm{H}_{2}$ ve $\mathrm{H}_{5}$ hipotezleri de kabul edilmiştir.

Araştırma için seçilen ilin sadece Konya ile sınırlı olması ve sadece bankacllık sektöründe uygulanması araştırmanın sınırlılıkları olarak değerlendirilebilir. Farklı bölge ya da sektörlerle yapılacak çalışmaların ilgili literatüre katkı sağlayacağı düşünülmektedir.

Ayrıca araştırmada ele alınan değişkenlerin birarada ele alındığı bir model bulunmadığından literatürdeki bu boşluğun giderilmesiyle katkı sağlanması amaçlanmaktadır. 


\title{
EXTENDED ABSTRACT
}

\section{The Mediator Role of Organizational Stress on The Effect of Organizational Uncertainty on Organizational Commitment}

\author{
Ayşe Elif Yazgan - Ebru Özer Topaloğlu \\ Necmettin Erbakan University
}

Today, as a result of rapid changes in businesses and technology, uncertainties emerge for managers and employees in organizations. Organizational uncertainties in business life also cause organizational stress. The stress experienced in organizations affects the organizational commitment of the employees. Stress can be seen as an individual's reaction to pressure. Fluctuations in business life and economy cause uncertainty and thus organizational stress (Weinberg, et al., 2010). Organizational commitment is described as an employee's desire to remain a member of the organization. Organizational commitment affects an employee staying as a member of the organization or leaving his current job for another job (Colquitt, et al., 2015).

The mediator role of organizational stress was tried to be determined in the effect of organizational uncertainty on organizational commitment in the banking sector, where time pressure and competition are highly felt by the employees in the study,. In this study, applied to bankers working in the central districts of Konya, the perceptions and relationships of bankers about organizational uncertainty, organizational commitment and organizational stress were measured, and the mediating role of organizational stress was investigated through the effect of organizational uncertainty on organizational commitment. No other study examining these three concepts together was found in the literature. However, when the literature was reviewed, it was determined that these three concepts might be related. Therefore, the relationship of these three concepts has been explored in the banking sector, where internal and external pressure is heavy.

The first study to be seen in the literature review on organizational uncertainty, organizational stress and organizational commitment, which is the 
subject of the research, is the study of Duncan (1972) on perceived uncertainty. Also examining the concept of uncertainty and organizational uncertainty in a cultural context (Faucheux, 1977; Hofstede 1980; Grote, 2007); organizational uncertainty and organizational stress to the effect of organizational change and organizational justice (Bordia, et al., 2004; Rafferty and Griffin, 2006); There are also studies investigating the relationship between organizational stress and organizational commitment (Boshooff \& Mells, 1995; Ioannis and Ioannis, 2002; Chen, et al., 2006; Lou, et al., 2007; Uzun \& Yiğit, 2011;). When we look at the literature, the relation between organizational uncertainty, organizational stress and organizational commitment are examined separately. In this study, it was aimed to contribute to the literature by investigating the mediating role of organizational stress in the effect of organizational uncertainty on organizational commitment, which has not been studied in the literature.

The hypotheses developed after examining the literature related to the research are as follows:

- H1: There is a significant and negative relationship between organizational uncertainty and organizational commitment.

- H2: Organizational uncertainty affects organizational commitment significantly and negatively.

- H3: There is a significant and positive relationship between organizational uncertainty and organizational stress.

- H4: There is a significant and negative relationship between organizational stress and organizational commitment.

- H5: Organizational stress has a mediating role in the effect of organizational uncertainty on organizational commitment.

There are four sections in the questionnaire prepared for the test of hypotheses. In the first part, there are demographic questions created to determine the characteristics of the participants such as gender, age, educational status, location, bank worked, monthly income. In the second part, the scale consisting of 17 expressions developed by Theorelli et al. (1988) and adapted to Turkish by Yildırım et al. (2011) was used to measure the organizational stress levels. The Cronbach Alpha value of the scale in this study was found to be 0.77. In the third part, the scale developed by Schweiger and Denisi (1991) and adapted to Turkish by Tinaztepe (2010) and validity and reliability was used from Polat (2015) in measuring organizational uncertainty levels. The 
Cronbach Alpha value of the scale consisting of 21 expressions was found to be 0,859 . In the fourth section, the scale developed by Allen-Meyer (1990) and revised by Meyer et al. (1993) was used from Boylu et al. (2007) to measure the levels of organizational commitment. The Cronbach Alpha value of the scale consisting of 17 expressions was found to be 0.888 .

Data entry was made using the IBM SPSS 25 package program. While analyzing the data, analysis was done with the structural equation model in order to analyze factor related to variables, correlation analysis in determining the relationships between variables and to examine the mediating effect of organizational uncertainty on organizational stress and organizational commitment.

In this study, the relationship between organizational uncertainty, organizational commitment and organizational stress experienced by the employees; organizational stress has been found to have a mediating effect in the relationship between organizational uncertainty and organizational commitment.

According to the correlation analysis conducted within the scope of the research, social support, which is one of the sub-dimensions of organizational stress, general uncertainty of causal relationships from sub-dimensions of organizational support, the lack of information, and the long time of feedback; Emotional commitment, which is one of the sub-dimensions of organizational commitment, was negatively related to normative commitment dimensions. Decision-making from sub-dimensions of organizational stress, general uncertainty of causal relationships from sub-dimensions of organizational uncertainty, lack of information is moderately positive; emotional commitment, which is one of the sub-dimensions of organizational commitment, was negatively related to normative commitment dimensions. The workload, which is one of the sub-dimensions of organizational stress, is positively weak with the dimension of long-term feedback from sub-dimensions of organizational uncertainty; It was observed that the sub-dimensions of organizational commitment were negatively related to the continuation commitment dimension. Skill usage from sub-dimensions of organizational stress, general uncertainty of causal relationships from sub-dimensions of organizational uncertainty, lack of knowledge are positively weak; Among the sub- 
dimensions of organizational commitment, emotional commitment is moderately negative with normative commitment dimensions; It was also found to be negatively related to the continuance commitment dimension.

\section{Kaynakça / References}

Aldag, R. J., ve Storey, R. G. (1975, August). Environmental uncertainty: Comments on objective and perceptual indices. In Academy of Management Proceedings (Vol. 1975, No. 1, p. 203-205). Briarcliff Manor, NY 10510: Academy of Management. https://doi.org/10.5465/ambpp.1975.4982411

Allen, N. J., ve Meyer, J. P. (1990). The Measurement and antecedents of affective, continuance and normative commitment to the organization. Journal OfOccupational Psychology, 63, 1-18. https://doi.org/10.1111/j.20448325.1990.tb00506.x

Angle, H. L., ve Perry, J. L. (1983). Organizational commitment: Individual and organizational influences. Work and Occupations, 10(2), 123-146. https://doi.org/10.1177\%2F0730888483010002001

Balay, R. (2000). Yönetici ve öğretmenlerde örgütsel bağhllık. Ankara: Nobel Yayın Dağıtim.

Baron, R. M., ve Kenny, D. A. (1986). The moderator-mediator variable distinction in social psychological research - conceptual, strategic, and statistical considerations. Journal of Personality and Social Psychology, 51(6), 1173-1182. https://psycnet.apa.org/doi/10.1037/0022-3514.51.6.1173

Blau, G. J., ve Boal, K. B. (1987). Conceptualizing how job involvement and organizational commitment affect turnover and absenteeism. Academy of management review, 12(2), 288-300. DOI: 10.2307/258536

Bordia, P., Hunt, E., Paulsen, N., Tourish, D., ve DiFonzo, N. (2004). Uncertainty during organizational change: Is it all about control?. European Journal of Work and Organizational Psychology. 13(3), 345-365. https://doi.org/10.1080/13594320444000128

Boshoff, C. veMels, G. (1995). A causal model to evaluate the relationships among supervision, role stress, organizational commitment and internal service quality. European Journal of Marketing, 29(2), 23-42. https://doi.org/10.1108/03090569510080932

Boylu, Y, Pelit, E. ve Güçer, E. (2007). Akademisyenlerin örgütsel bağlllık düzeyleri üzerine bir araştırma. Finans Politik \& Ekonomik Yorumlar, 44 (511), 55-74.

Büyüköztürk, Ş. (2007). Sosyal bilimler için veri analizi el kitabı (12. baskı). Ankara: Pegem A Yayınları. 
Chen, J. C., Silverthorne, C., ve Hung, J. Y. (2006). Organization communication, job stress, organizational commitment, and job performance of accounting professionals in Taiwan and America. Leadership \& Organization Development Journal. 242-249. DOI 10.1108/01437730610666000

Colquitt, J., Lepine, J. A., Wesson, M. J., ve Gellatly, I. R. (2015). Organizational behavior: Improving performance and commitment in the workplace (4th Edition). New York, NY: McGraw-Hill Irwin.

Cranwell-Ward, J., ve Abbey, A. (2005). Organizational Stress. Springer.

Çetin, M. Ö. (2004). Örgüt kültürü̈ ve örgütsel bağlllk. Ankara: Nobel Yayın Dağıtım.

Dinçman, M. P. (2016). Eğitim ve okul yönetiminde örgütsel belirsizlikle ilgili temel konulan ele alan bilimsel yayınlarm analizi 1990-2016. Doktora Tezi, Hacettepe Üniversitesi Eğitim Bilimleri Enstitüsü, Ankara.

Düzgün, A. (2014). Üst düzey yöneticilerde örgütsel stres ve örgütsel bağlllik ilişkisi analizi: Antalya bölgesi beş yıldızl otel işletmelerinde bir uygulama. Yüksek Lisans Tezi, Adnan Menderes Üniversitesi, Sosyal Bilimler Enstitüsü, Aydın.

Faucheux, C. (1977). Strategy formulation as a cultural process. International Studies of Management and Organization, 7(2), 127-138.

Ganster, D. C., Mayes, B. T., Sime, W. E., ve Tharp, G. D. (1982). Managing organizational stress: A field experiment. Journal of Applied Psychology, 67(5), 533. https://psycnet.apa.org/doi/10.1037/0021-9010.67.5.533

Grote, G. (2007). Understanding and assessing safety culture through the lens of organizational management of uncertainty. Safety science, 45(6), 637-652. https://doi.org/10.1016/j.ssci.2007.04.002

Güney, S. (2007). Yönetim ve organizasyon (2. Baskı). Ankara: Nobel Yayınları.

Hall, D. T., Schneider, B., ve Nygren, H. T.(1970).Personal factors in organizational identification. Administrative Science Quarterly, 25, 176-1. DOI: $10.2307 / 2391488$

Hofstede, G. (1980).Culture's consequences: international differences in work related values. Sage: Beverly Hills, CA.

Hui, C., ve Lee, C. (2000). Moderating effects of organization-based self-esteem on organizational uncertainty: Employee response relationships. Journal of Management, 26(2), 215-232. https://doi.org/10.1177\%2F014920630002600203

Karakuş, Ş. ve Yardım, M. (2014). Algilanan örgütsel değişim, belirsizlik, iş doyumu ve işten ayrılma niyeti arasındaki ilişkileri. İş ve İnsan Dergisi, 1(1), 21-31. doi: 10.18394/iid.50336

Kline, P. (1994). An easy guide to factor analysis. UK: Routledge. 
Lou, J. H., Yu, H. Y., Hsu, H. Y., ve Dai, H. D. (2007). A study of role stress, organizational commitment and intention to quit among male nurses in Southern Taiwan. The Journal of Nursing Research: JNR, 15(1), 43-53. https://doi.org/10.1097/01.jnr.0000387598.40156.d2

Meyer, J. P., Allen, N. J. ve Smith, C. A. (1993). Commitment to organizations and occupations: Extension and test of a threecomponent conceptualization. Journal Of Applied Psyhology, 78(4), 538-551. https://psycnet.apa.org/doi/10.1037/0021-9010.78.4.538

Mowaday, R. T., Porter, L. W., ve Steers, R. M. (1982). Employee-organization linkages: The Psychology Of Commitment, Absenteeism and Turnover. Academic Press.

Nikolaou, I., ve Tsaousis, I. (1993-2002). Emotional intelligence in the workplace. Exploring its effects on occupational stress and organizational commitment. International Journal of Organizational Analysis, 10(4), 327.

Özutku, H. (2008). Örgüte duygusal, devamlılık ve normatif bağlllık ile iş performansı arasındaki ilişkinin incelenmesi. İstanbul Üniversitesi İsletme Fakültesi Dergisi, 37(2), 79-97.

Polat, M. (2015). Yöneticilerin açık liderlik özellikleri ve sosyal ağlar benimseme durumlarnın örgütsel belirsizlik üzerindeki etkileri: Fırat Üniversitesi örneği. Yayımlanmamış Doktora Tezi, Fırat Üniversitesi, Eğitim Bilimleri Enstitüsü, Eğitim Yönetimi Teftişi Planlaması ve Ekonomisi ABD, Elazı̆̆.

Polat, M., ve Arabacı, İ. B. (2015). Enformasyon kuramı bağlamında sosyal ağlar. Örgütsel belirsizlik ve eğitim: Kavramsal Bir Analiz. Journal of International Social Research, 8(37).

Rafferty, A. E., ve Griffin, M. A. (2006). Perceptions of organizational change: A stress and coping perspective. Journal of applied psychology, 91(5), 1154.

Salancik, G. R. (1977). Commitment and the control of organizational behavior and belief. New directions in organizational behavior, 1, 54 .

Schermelleh-Engel, K., Moosbrugger, H. ve Müler, H. (2003). Evaluating the fit of structural equation models: Tests of significance and descriptive goodness-of-fit measures. Methods of Psychological Research Online 8(2), 23-74.

Schweiger, D. M., ve Denisi, A. S. (1991). Communication with employees following a merger: a longitudinal field experiment. Academy of Management Journal, 34(1), 110-135. https://doi.org/10.5465/256304

Sökmen, A. (2010). Yönetim ve organizasyon. Ankara: Detay Yayıncllk.

Stanley Budner, N. Y. (1962). Intolerance of ambiguity as a personality variable. Journal of Personality, 30(1), 29-50. 
Sutherland, V.J. and Cooper, C.L. (2000) Strategic stress management: an organisational approach. Basingstoke: Macmillan - now Palgrave Macmillan.

Tett, R. P., ve Meyer, J. P. (1993). Job Satisfaction, organizational commitment, turnover intention and turnover: Path analyses based on meta-analytic findings. Personnel Psychology, 46(2), 259-293. https://doi.org/10.1111/j.17446570.1993.tb00874.x

Theorell, T., Perski, A., Akerstedt, T. ve ark. (1988). Changes in job strain in relation to changes in physiological state. Scand J Work Environ Health, 14, 189-196.

Tinaztepe, C. (2010). The effect of desire for change on the relationship between perceived uncertainty and job related affective well being. Yayımlanmamış Yüksek Lisans Tezi. Sosyal Bilimler Enstitüsü, Örgütsel Davranış Bilim Dalı, Marmara Üniversitesi, İstanbul.

Türk Dil Kurumu (TDK). 2020a. Stres. 15.02.2020 tarihinde http://www.tdk.gov.tr adresinden erişilmiştir.

Türk Dil Kurumu (TDK). 2020b. Belirsizlik. 17.02.2020 tarihinde http://www.tdk.gov.tr adresinden erişilmiştir.

Uzun, Ö., ve Yiğit, E. (2011). Örgütsel stres ve örgütsel bağlılık ilişkisi üzerine orta kademe otel yöneticileri üzerinde yapılan bir araştırma. Eskişehir Osmangazi Üniversitesi İ̈BF Dergisi, 6(1), 181-213.

Weinberg, A., Bond, F., Cooper, C., ve Sutherland, V. J. (2010). Organizational stress management: A strategic approach. Palgrave Macmillan.

Yıldırım, Y., Taşmektepligil, M.Y., ve Üzüm, H. (2011). Kısa versiyon örgütsel stres ölçeğinin Türkçeye uyarlanması. Selçuk Üniversitesi Beden Eğitimi ve Spor Bilim Dergisi, 13 (1), 103-108.

Zencirkıran, M., ve Keser, A. (2018). Örgütsel davranıs, değerlemesi ve yönetimi. Bursa: Dora Basım Yayın.

Zengin, Y.(2019). Dönüştürücü liderlik ile rekabet üstünlüğü performansı arasındaki ilişkide etkileşimsel liderliğin aracılık rolü. OPUS-Uluslararası Toplum Araştırmalarn Dergisi, 11(18), 1325-1355. DOI: 10.26466/opus.552141.

\section{Kaynakça Bilgisi / Citation Information}

Yazgan, A. E. ve Topaloğlu Özer, E. (2020). Örgütsel belirsizliğin örgütsel bağlılık üzerindeki etkisinde örgütsel stresin aracılık rolü. OPUSUluslararası Toplum Araştırmaları Dergisi, 16(28), 1272-1295. DOI: 10.26466/opus.748687 